\title{
Tema y variación: hombres a los cuarenta
}

\author{
Juan Carlos CALVILlo ReYes \\ Universidad Nacional Autónoma de México
}

\begin{abstract}
En la tradición occidental han sido numerosos los poetas que aprovechan su llegada a una cierta edad para escribir reflexiones o confesiones en torno a su experiencia de vida. La presente antología mínima ofrece, en original y traducción al español, poemas de Donald Justice, Joseph Brodsky y Derek Walcott en los que el cuadragésimo aniversario brinda la oportunidad de estimar en términos líricos la resignación de la madurez, las penurias del exilio y la perseverante entrega al oficio de la poesía.
\end{abstract}

PALABRAS CLAVE: tema y variación, poesía autobiográfica, cumpleaños, madurez, traducción.

In the Western tradition, many poets have taken advantage of their arrival to a certain age to write confessions or meditations on their life and experience. This minimal anthology offers, both in their original English language and in translation into Spanish, poems by Donald Justice, Joseph Brodsky, and Derek Walcott in which the fortieth birthday is seized as an opportunity to gauge in lyrical terms the resignation imposed by maturity, the penuries of exile, and the persevering commitment to the art of poetry.

KEY WORDS: Variations upon a theme, autobiographical or confessional poetry, birthday, maturity, translation.

El cumpleaños como pretexto o justificación de un poema que recapitula la experiencia de una vida es un motivo recurrente en el enfrentamiento del hombre con su propia existencia. No es entonces de sorprender, me parece, que un grupo tan variado de poetas como el que hace poco atrajo mi atención haya encontrado en el advenimiento de una edad liminar, en el cruce inevitable de un determinado umbral de madurez, una ocasión de volver la mirada con la esperanza de aquilatar el breve paso del hombre por este mundo.

Los tres poemas que he recopilado, y cuya traducción presento enseguida, conforman una selección mínima, y por tanto injusta, de líricas confesionales que se valen del arribo a una cierta edad para hacer un balance de las victorias y derrotas del pasado. Y digo injusta porque, bajo esta misma tónica, cabría citar a una enorme diversidad de poetas no menos distinguidos, desde Anacreonte de Teos, cuyos fragmentos a menudo 
lamentan la cercanía de la vejez y la muerte, hasta el propio Philip Larkin, cuyo "Maturity" ("Madurez") parecería una elección insoslayable. No obstante, los tres poemas del presente repertorio se vinculan de un modo particular no sólo porque comparten la curiosa certeza de ser autobiográficos y la todavía más curiosa coincidencia de la exactitud en la cifra del aniversario; se presentan como antología, en el sentido más etimológico de la palabra, porque ofrecen formas diametralmente distintas de tratar un mismo tema.

El interés de la recopilación, luego entonces, radica en el tono. "Men at Forty" ("Hombres a los cuarenta"), del estadounidense Donald Justice, es un poema que pareciera tranquilo y sosegado y, sin embargo, que sorprende con un golpe final. La suavidad y homofonía de la primera estrofa, aunadas a la exhaustiva generalización del título, hacen que el texto simule una proposición ecuménica. Saber que Justice tenía cuarenta años a la fecha de su composición se vuelve un dato cada vez más relevante conforme aumenta la velocidad en el poema: la cuarta estrofa se encabalga con la quinta, los términos something ("algo") y filling ("llena") se repiten, y la primera imagen sonora, el chirrido de los grillos, se adivina casi un presagio. La palabra más sorprendente, la más imprevisible, es sin duda la penúltima, mortgaged ("hipotecadas"): al cabo del poema es ineludible el desasosiego, la dominante sensación de que algo más se ha hipotecado aparte de la casa: la sensación que recuerda, de manera también etimológica, la "garantía de muerte" que se firma con la madurez.

"May 24, 1980" ("24 de mayo de 1980"), del exiliado ruso Joseph Brodsky, se ofrece como una suerte de apología o proclamación de agradecimiento, en palabras de Thoreau, por "vivir deliberadamente". La fortuna y la desgracia, la gratitud y el perdón, se conjugan en el poema de Brodsky para impregnar al lector de un resabio agridulce. Autorreferencial y enigmático, traducción a su vez del ruso, el poema está lleno de imágenes poco usuales ("rake my nitty-gritty", verso 6), ambigüedades deliberadas ("lived by the sea", verso 3) y juegos de palabras ("aces in an oasis", verso 3) que redundan en un efecto de exotismo lingüístico; un exotismo análogo, por cierto, a la peculiari-dad o extravagancia de la propia experiencia de vida que se recuenta en el poema.

En "Nearing Forty" ("Cerca de los cuarenta"), la llegada al cuadragésimo aniversario es nuevamente el impulso que aprovecha el poeta santaluciano Derek Walcott para afrontar, reconocer y aceptar su propia existencia, una existencia que encuentra su razón y reflejo en el oficio de la poesía. La única oración que conforma el poema se complementa en gran medida, sin embargo, con la lectura del epígrafe del Dr. Samuel Johnson, lectura que, a su vez, se retroalimenta del poema de Walcott. Es sólo mediante el reconocimiento de la influencia estilística clasicista que el poema cobra un nuevo significado, el de la lucha del escritor por liberarse de la imitación en su búsqueda de la creación genuina.

La oposición de incandescencia, oscuridad y humedad encuadra, en el poema de Walcott, la retrospectiva anticipada de un "día en que [se] pueda juzgar [el] trabajo" de una vida que "sangró por / la verdad" (versos 6-10). Tal como advierte el epígrafe, 
el duelo se debate entre el ingenuo romanticismo de la juventud y "la estabilidad de [una] verdad" no imitativa que, en términos formales, halla su última envergadura en la frustración y subsecuente emancipación de un estilo heredado. El forcejeo con los pareados heroicos y la normativa dieciochesca conduce al poeta al fracaso, y no es sino hasta el momento en que el artista abandona su esfuerzo mimético ("o te levantarás y pondrás tus versos a trabajar”, verso 25) que el poema adquiere una nueva fuerza, la energía de la creación auténtica.

El criterio que rige la traducción de esta antología tiene como objeto la presentación de versiones que se lean como poemas por derecho propio, de modo individual desde luego, pero, más oportunamente, como partes constitutivas del discurso que he presentado aquí a manera de exordio. La adopción de tal propósito implica ya que ciertos principios de eufonía y estilo se privilegian sobre consideraciones, no menos importantes, de precisión, literalidad o incluso lo que candorosamente ha llegado a considerarse exactitud. El caso de pérdida más lamentable a costa de dicha empresa - puesto que, en cuanto a la forma se refiere, fue posible la conservación de lo ominoso en Justice y lo exótico en Brodsky - es sin duda el de Derek Walcott, sin cuya pugna con la métrica estricta del pareado heroico la traducción no logra explotar la significación potencial o total del texto. "Nearing Forty" es un poema de fracasos y desencuentros, sin embargo, y de hallazgos de cara a la derrota. Es por esta razón que confío, citando al propio Walcott, en poner a trabajar "versos simples y brillantes", y, en consecuencia, ofrezco al lector esta traducción con la esperanza de que encuentre en ella también "el chisporroteo / de la lucidez ocasional".

El arribo a una determinada edad, sea la cifra que sea, es, como bien sabemos, una imposición del todo artificial en el transcurso de la vida. "Sé lo que es el tiempo si nadie me lo pregunta", decía san Agustín, y, sin embargo, hay algo revelador en el hecho de que llevemos escrupulosamente la cuenta, algo que delata nuestro afán de que esa cantidad no sea tan sólo un monto sino, en efecto, una suma. Sería una pena verse obligado a aceptar que todo el tesoro de la lozanía mora en lo profundo de unos ojos hundidos por los años, escribe Shakespeare en un soneto famoso, "cuando sean ya cuarenta los inviernos que asedien tu frente / y caven surcos en la huerta de tu belleza". Para desafiar esa pena, para vencer al gran enemigo que es el paso del tiempo, y para no entrar dócilmente en esa noche quieta, está siempre el arte de la poesía. 


\title{
MEN AT FORTY
}

Donald Justice

\author{
Men at forty \\ Learn to close softly \\ The doors to rooms they will not be \\ Coming back to.
}

At rest on a stair landing,

They feel it moving

Beneath them now like the deck of a ship,

Though the swell is gentle.

And deep in mirrors

They rediscover

The face of the boy as he practices tying

His father's tie there in secret,

And the face of that father,

Still warm with the mystery of lather.

They are more fathers than sons themselves now.

Something is filling them, something

That is like the twilight sound

Of the crickets, immense,

Filling the woods at the foot of the slope

Behind their mortgaged houses. 


\section{HOMBRES A LOS CUARENTA}

Los hombres a los cuarenta

aprenden a cerrar con suavidad

las puertas que dan a habitaciones

a las que nunca volverán.

Descansan en el rellano de una escalera

y sienten cómo se mueve ahora

bajo sus pies como la cubierta de un barco, aunque el oleaje no es fuerte.

Y en la profundidad de los espejos

vuelven a descubrir

el rostro del niño que practica un nudo

en la corbata de su padre, allí en secreto,

y el rostro de aquel padre,

aún tibio con el misterio de la espuma de afeitar.

Ellos mismos son ahora más padres que hijos.

Algo los llena, algo

que es como el sonido crepuscular

de los grillos, inmenso,

que llena los bosques al pie de la colina

detrás de sus casas hipotecadas. 
MAY 24, 1980

Joseph Brodsky

I have braved, for want of wild beasts, steel cages, carved my term and nickname on bunks and rafters, lived by the sea, flashed aces in an oasis, dined with the-devil-knows-whom, in tails, on truffles.

From the height of a glacier I beheld half a world, the earthly width. Twice have drowned, thrice let knives rake my nitty-gritty. Quit the country that bore and nursed me.

Those who forgot me would make a city.

I have waded the steppes that saw yelling Huns in saddles, worn the clothes nowadays back in fashion in every quarter, planted rye, tarred the roofs of pigsties and stables, guzzled everything save dry water.

I've admitted the sentries' third eye into my wet and foul dreams. Munched the bread of exile; it's stale and warty.

Granted my lungs all sounds except the howl; switched to a whisper. Now I am forty.

What should I say about my life? That it's long and abhors transparence. Broken eggs make me grieve; the omelet, though, makes me vomit.

Yet until brown clay has been rammed down my larynx, only gratitude will be gushing from it. 


\section{DE MAYO DE 1980}

He desafiado, a falta de bestias salvajes, jaulas de acero, tallado mi término y apodo en vigas y literas, vivido por el mar, mostrado ases en un oasis, cenado trufas, de frac, con no sé quién diablos.

Desde lo alto del glaciar he contemplado medio mundo, la amplitud de la tierra. Dos veces me he ahogado, tres he dejado que navajas rastrillen mis asuntos.

Abandonado el país que me parió y me nutrió.

Todos los que me han olvidado podrían fundar una ciudad.

He caminado las estepas que vieron hunos gritando en sus monturas, vestido la ropa que ahora vuelve a ponerse de moda en todos lados, sembrado centeno, alquitranado los techos de establos y chiqueros, tragado de todo salvo agua seca.

He admitido el tercer ojo de los centinelas en mis sueños húmedos y obscenos. Mascado el pan del exilio: es rancio y grumoso. Le he concedido a mis pulmones toda voz salvo el aullido; he pasado al murmullo. Ahora tengo cuarenta años. ¿Qué podría decir de la vida? Que es larga y que aborrece la transparencia. Sufro por los huevos rotos; el omelet, sin embargo, me hace vomitar. Aun así, hasta que tenga la laringe atascada de tierra parda, lo único que brotará de ella es gratitud. 
NEARING FORTY

Derek Walcott

[for John Figueroa]

The irregular combination of fanciful invention may delight awhile by that novelty of which the common satiety of life sends us all in quest. But the pleasures of sudden wonder are soon exhausted and the mind can only repose on the stability of truth...

SAMUEL JOHNSON

Insomniac since four, hearing this narrow, rigidly metred, early-rising rain

recounting, as its coolness numbs the marrow, that I am nearing forty, nearer the weak vision thickening to a frosted pane, nearer the day when I may judge my work by the bleak modesty of middle age as a false dawn, fireless and average, which would be just, because your life bled for the household truth, the style past metaphor that finds its parallel however wretched in simple, shining lines, in pages stretched plain as a bleaching bedsheet under a guttering rainspout; glad for the sputter of occasional insight, you who foresaw ambition as a searing meteor will fumble a damp match and, smiling, settle for the dry wheezing of a dented kettle, for vision narrower than a louvre's gap, then, watching your leaves thin, recall how deep prodigious cynicism plants its seed, gauges our seasons by this year's end rain which, as greenhorns at school, we'd call conventional for convectional; or you will rise and set your lines to work with sadder joy but steadier elation, until the night when you can really sleep, measuring how imagination 


\title{
CERCA DE LOS CUARENTA
}

[para John Figueroa]

\begin{abstract}
Las maniobras irregulares del ingenio imaginativo pueden deleitar un tiempo dado que ofrecen aquella novedad en pos de la cual el hartazgo común de la vida nos pone a todos en busca. Pero los placeres del asombro repentino se extinguen pronto y la mente puede sólo reposar en la estabilidad de la verdad...
\end{abstract}

Insomne desde las cuatro, escuchando cómo arrecia esta lluvia prematura, cerrada, rigurosamente medida, contando, al tiempo que su frialdad entumece la médula, que estoy ya cerca de los cuarenta, más cerca de la vista débil que se engrosa hasta volverse un cristal escarchado, más cerca del día en que pueda juzgar mi trabajo con la sombría modestia de la madurez como un falso amanecer, mediocre y sin fuego, que sería justo, porque tu vida sangró por la verdad doméstica, el estilo más allá de la metáfora que encuentra su paralelo, por desdichado que sea, en versos simples y brillantes, en páginas lisas tendidas como una sábana blanqueada bajo una canaleta para la lluvia; contento con el chisporroteo de la lucidez ocasional, tú que previste la ambición como un meteoro abrasador buscarás a tientas un fósforo mojado y, sonriendo, te conformarás con el seco silbido de una tetera abollada, con la vista más estrecha que una rendija entre persianas, y luego, viendo cómo adelgazan tus hojas, recordarás cuán profundamente el prodigioso cinismo siembra su semilla, calcula nuestras estaciones con la postrera lluvia de este año que, cual novatos en la escuela, llamaríamos convencional en lugar de conveccional; o te levantarás y pondrás tus versos a trabajar con una alegría más triste pero con regocijo constante, hasta la noche en que puedas dormir de verdad, midiendo cómo la imaginación 
$254 \square$ TEMA Y VARIACIÓN: HOMBRES A LOS CUARENTA

ebbs, conventional as any water clerk who weighs the force of lightly falling rain,

which, as the new moon moves it, does its work even when it seems to weep. 
disminuye, convencional como un marino cualquiera que mide la fuerza de la lluvia cayendo ligera, que, movida por la luna nueva, hace su trabajo incluso cuando pareciera llorar. 
$256 \square$ TEMA Y VARIACIÓN: HOMBRES A LOS CUARENTA

Obras citadas

Brodsky, Joseph. 2002. Collected Poems in English. Nueva York: Farrar, Straus \& Giroux.

Justice, Donald. 2006. Collected Poems. Nueva York: Knopf.

WalcotT, Derek. 1987. Collected Poems 1948-1984. Nueva York: Farrar, Straus \& Giroux. 